\title{
300 Jahre Johann Christian Senckenberg und 2007, das SenCKenderg-Jahr in Frankfurt am Main
}
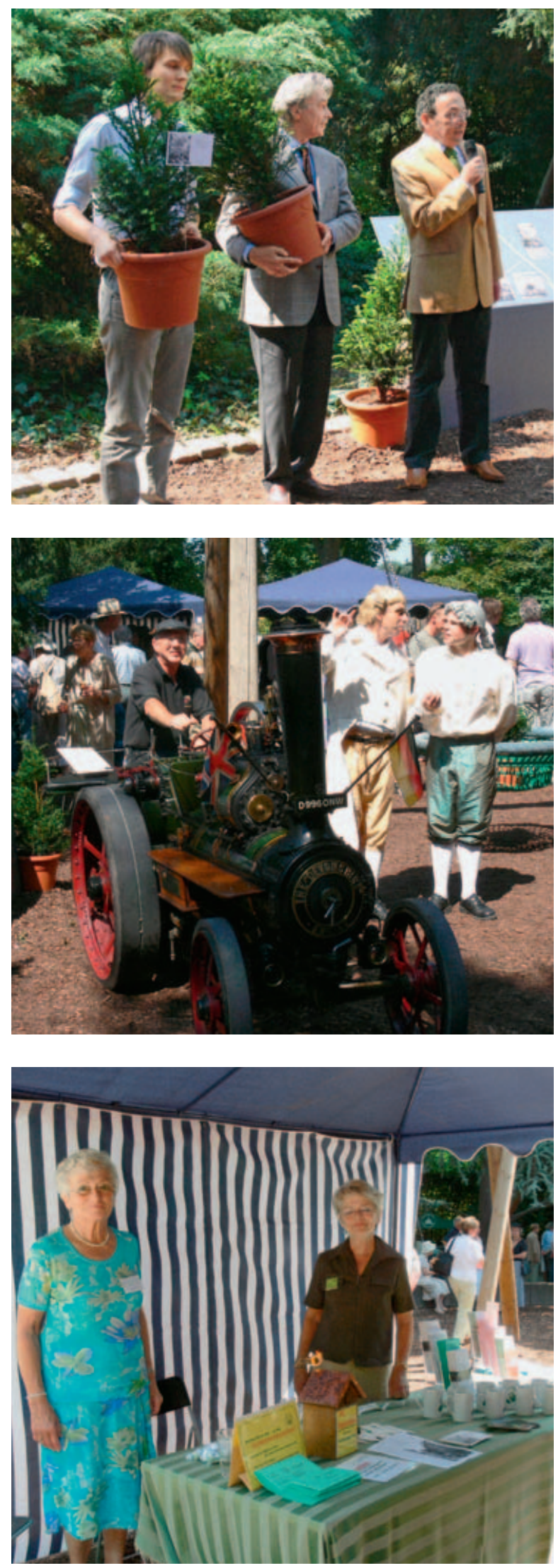

Am 15. Juli 2007 wurde im Rahmen eines Festaktes eine Gedenktafel an der 400-jährigen Eibe im Palmengarten enthüllt. Die Tafel erinnert daran, dass im Mai 1907 der damals 300-jährige Baum vom ehemaligen SENCKENBERG-Stift am Eschenheimer Turm in einer spektakulären Verpflanzungsaktion in den neuen botanischen Garten gebracht wurde. Das Gelände, auf dem die Eibe steht, gehört inzwischen zum Palmengarten. Deshalb fand das fröhliche Fest mit Schauspiel, Musik und einer Dampfwalzenfahrt im Palmengarten zwischen Goethe-Garten und Wasserspielplatz statt.

Abb. 1 (links oben): Enthüllung der Gedenktafel und Übergabe von jungen Eibenbäumen an die Mitwirkenden. S. Herkner, K. Schopow und M. Jenny.

Abb. 2 (links Mitte): Goethe trifft den Stadtmedicus Senckenberg. Die Schauspieler Thomas Morawietz und Sebastian Huther von der Dramatischen Bühne.

Abb. 3 (links unten): Herta Menk und Dorrit Röhnert von der Palmengartengesellschaft stehen mit Rat und Information zur Seite.

Abb. 4 (rechts unten): Von links nach rechts: Dr. Matthias Jenny, Sebastian Herkner (Dipl.-Designer, hat den Entwurf für die Gedenktafel erstellt), Dr. Kosta Schopow (Vorsitzender der Dr. Senckenbergischen Stiftung)

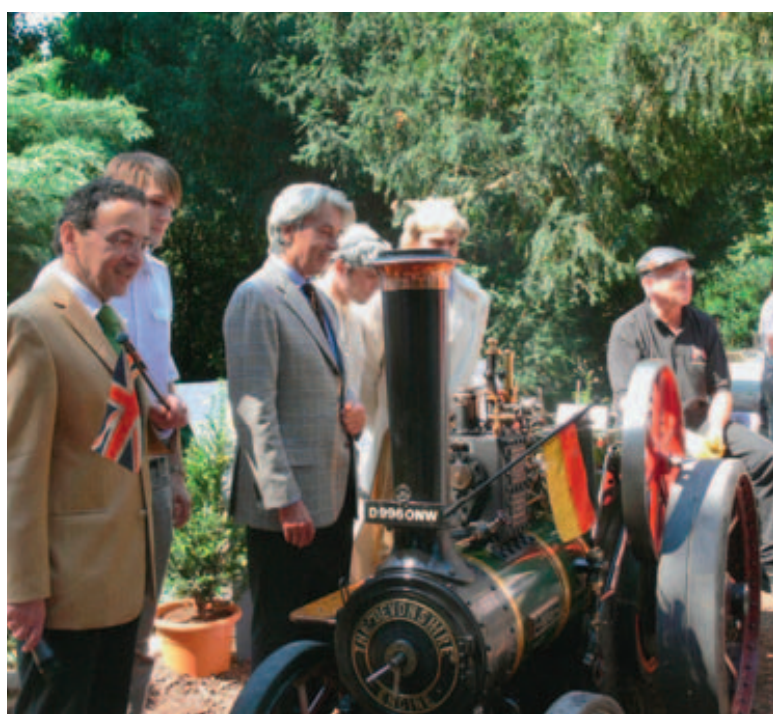

